\title{
Myocardial protection by interferon- $\gamma$ late preconditioning during cardiopulmonary bypass-associated myocardial ischemia-reperfusion in pigs
}

\author{
XIANGANG YAN $^{1}$, WANSHAN QIU ${ }^{1}$, BING JIA ${ }^{1}$, HUI ZHONG $^{1}$, XIN LI $^{2}$ and ZHANGGEN CHEN ${ }^{1}$ \\ ${ }^{1}$ Division of Cardiovascular and Thoracic Surgery, Children's Hospital of Fudan University, Shanghai 201102; \\ ${ }^{2}$ Division of Cardiothoracic Surgery, Department of Surgery, The University of Hong Kong, \\ Pokfulam, Hong Kong, SAR, P.R. China
}

Received June 26, 2013; Accepted August 1, 2013

DOI: 10.3892/or.2013.2707

\begin{abstract}
The impact of interferon- $\gamma(\mathrm{IFN}-\gamma)$ late preconditioning on myocardial ischemia-reperfusion injury during cardiopulmonary bypass (CPB) and the underlying mechanism were investigated. Using a porcine model of myocardial ischemia-reperfusion injury during CPB with a 60-min aorta cross-clamp, 20 pigs $(15 \pm 0.5 \mathrm{~kg})$ were treated randomly with either a $1-\mathrm{ml}(20,000 \mathrm{IU} / \mathrm{kg}) \mathrm{IFN}-\gamma$ injection (IFN- $\gamma$ group; $\mathrm{n}=10$ ) or saline solution (control group; $\mathrm{n}=10$ ) $24 \mathrm{~h}$ prior to CPB. Heart rate, blood pressure, left ventricular end-systolic pressure (LVESP), left ventricular end-diastolic pressure (LVEDP), creatine kinase isoenzyme-MB (CK-MB), and cardiac troponin I (cTnI) were measured before $\mathrm{CPB}$, before aortic clamping, and at post-reperfusion intervals of 10, 30, 60 and $120 \mathrm{~min}$. Heat shock protein 70 (HSP70), Mn-superoxide dismutase (Mn-SOD) and inducible nitric oxide synthase (iNOS) were measured by immunohistochemical staining in pre-CPB myocardial tissues. Myocardial cell apoptosis TUNEL measurement was assessed in samples obtained 60 min following reperfusion. Both groups exhibited no statistical differences in age, weight, gender and preoperative cardiac function, and worsened left ventricular function, and hemodynamic index reductions, and significant $\mathrm{cTnI}$ and CK-MB leakage was observed 10 and $30 \mathrm{~min}$ after reperfusion. At 10, 30 and 60 min following reperfusion, ventricular function and leakage of the IFN- $\gamma$ group were significantly improved, and expression of HSP70, iNOS and Mn-SOD increased and myocardial cell apoptosis decreased. IFN- $\gamma$ late preconditioning exhibited preventative effects on myocardial tissues in pigs during CPB surgery, likely due to increased HSP70, Mn-SOD and iNOS expression.
\end{abstract}

Correspondence to: Dr Bing Jia, Division of Cardiovascular and Thoracic Surgery, Children's Hospital of Fudan University, No. 399 Wanyuan Road, Shanghai 201102, P.R. China E-mail: jiabing2013@126.com

Key words: interferon- $\gamma$, late preconditioning, cardiopulmonary bypass, myocardial ischemia-reperfusion injury

\section{Introduction}

Myocardial ischemic-reperfusion occurs following ischemic treatment of acute coronary syndromes and cardiopulmonary bypass (CPB) (1). CPB is associated with postoperative organ dysfunction and cardiovascular instability due to the contact of blood components with artificial surfaces, aortic cross-clamping, allogeneic blood transfusion, and cardioplegic methods, often resulting in systemic inflammatory response syndrome (SIRS) (2). First developed in 1953, steady improvements in biocompatible materials, arterial filtering, membrane oxygenation and centrifugal blood pumping have reduced $\mathrm{CPB}$ mortality $(2,3)$, although the window for sustained ischemia before tissue damage occurs remains extremely narrow.

In myocardial ischemia, prompt blood flow restoration is the most significant factor for limiting infarct size and mortality. Reperfusion injury can result from delayed blood flow return (4), causing myocardial, vascular and electrophysiological dysfunctions that commonly result in arrhythmias, microvascular dysfunction, endothelial cell damage, myocardial stunning, death of myocytes and infarction (1). Following treatment with CPB for congenital heart disease, Egan et al (5) suggested that low cardiac output, the primary cause of morbidity following surgical intervention, was associated with tissue edema. Other research suggests that poor outcomes result from myocyte apoptosis caused by ischemic reperfusion mitochondrial activation (6). The pathophysiology of myocardial ischemic-reperfusion during CPB remains relatively unknown.

Ischemic-preconditioning (IPC) is endogenous myocardial protection involving natural defense mechanisms that, similar to related stress protein synthesis treatments, result in ischemia resistance (7). In 1986, Murry et al (8) first demonstrated that brief ischemic periods increase tissue tolerance for extended ischemia. In the 'classical' IPC framework, membrane receptors associated with adenosine, catecholamines, acetylcholine, bradykinin and opioids, are activated (9); whereas, the 'second window' framework suggests that gene expression is altered resulting in the release of cardioprotective heat shock proteins (HSPs) and antioxidases $(10,11)$. Interventions that target mediators, such as PKC agonists, and end-effectors, such as 
ATP-dependent potassium channel blockers are clinical IPC alternatives (7). Clinical applications of IPC may be beneficial when increasing the average critical ischemia time, defined as the duration of circulatory disruption compatible with $50 \%$ of tissue survival (11).

IPC pathophysiology is related to reduced loss of tissue high-energy phosphates during and post-ischemic pro-inflammatory neutrophil and mast cell-mediated microvascular injury, direct cellular toxicity of superoxide free radicals, platelet plugging and calcium overload (8). A variety of apoptosis-associated factors released during $\mathrm{CPB}$, including oxygen-free radicals, tumor necrosis factor- $\alpha$ (TNF- $\alpha$ ), nitric oxide (NO), and neurohumoral factor angiotensin II (AII) are mediated by IPC treatment (12-14).

Endogenous pyrogens (EPs), including interferon $\gamma$ (IFN)- $\gamma$, TNF- $\alpha$, interleukin (IL)-1, and IL-6, exhibit heating effects and acute phase responses that increase HSP70 production, resulting in transient ischemia protection (15) provided by various intracellular antioxidants (glutathione, tocopherol, ascorbic acid and $\beta$-carotene), antioxidant enzymes [Mn-superoxide dismutase (Mn-SOD)], catalase, glutathione (GSH) peroxidase and HSP mRNA promoters (IL-1 $\alpha$ and TNF) (16). Additionally, hypoxia and hypothermia increase levels of HSP70 and offer ischemia protection (16). Perfusion with a pro-inflammatory cytokine mixture consisting of IL-1 $\beta$, TNF- $\alpha$ and IFN- $\gamma$, similar to hypothermia stress proteins, for $120 \mathrm{~min}$ was found to increase HSP and inducible NO synthase (iNOS) mRNA formation $(17,18)$. Thus, IFN- $\gamma$ and TNF- $\alpha$ may be associated with body temperature increases in hypothermia and the subsequent acute phase response in HSP production to generate ischemic protection.

Electron microscopy is the conventional standard for detecting cardiac apoptosis, although use of in situ terminal deoxynucleotidyl-transferase-mediated dUTP nick end labeling (TUNEL) assay is now common. In this method fragmented DNA strands are stained and quantified, although overestimation of apoptotic nuclei may occur due to the labeling of both RNA and DNA fragments in both healthy and necrotic cells $(12,18)$.

The current study establishes an in vivo $\mathrm{CPB}$ and ischemic-reperfusion model using porcine subjects to assess the impact of IFN- $\gamma$ on ischemic-reperfusion injury during CPB over a 24-h period. Using ELISA and TUNEL assays, plasma troponin I (cTnI) and creatine kinase (CK-MB) levels were assessed, respectively. Additionally, expression levels of HSP70, Mn-SOD and iNOS were examined in sampled myocardial tissues in order to confirm the mechanism of ischemic-reperfusion injury.

\section{Materials and methods}

Animal subjects. Twenty local clean grade pigs $(15 \pm 0.5 \mathrm{~kg})$ aged 3-4 months of unspecified gender were provided by the Experimental Animal Center of Fudan University from stock at the breeding farm of the Shanghai Agricultural Institute (Shanghai, China) for use in the establishment of an animal model of CPB. All animal subjects were housed with ad libitum access to food (piglet pellet feed; Shanghai Xin-nong Feed, Shanghai, China) and filtered tap water under standard conditions of temperature $\left(22^{\circ} \mathrm{C}\right)$, humidity $(60 \%)$, and a 12-h light/dark cycle for a minimum of 3 days prior to the experiments. Animal subjects were randomly divided into 2 groups: the IFN- $\gamma$ group and the control group. The current study was conducted in accordance with the National Institutes of Health (NIH) Guide for the Care and Use of Laboratory Animals and was approved by the Fudan University Animal Care and Use Committee.

Establishment of the CPB model. At $24 \mathrm{~h}$ prior to surgery, IFN- $\gamma$ group subjects were treated with a subcutaneous injection of $20,000 \mathrm{IU} / \mathrm{kg}$ IFN- $\gamma$ dissolved in $1 \mathrm{ml}$ of saline solution, while control group subjects were injected with $1 \mathrm{ml}$ of saline solution. Food was withheld from all subjects for $12 \mathrm{~h}$ prior to surgery. Ketamine $(15-20 \mathrm{mg} / \mathrm{kg})$, diazepam $(0.5-1.0 \mathrm{mg} /$ $\mathrm{kg})$, and atropine $(1.0 \mathrm{mg}$ ) were injected intramuscularly for basal anesthesia, and intravenous access was established through the marginal vein of the ear. Simultaneously, the carotid artery was opened and punctured under direct vision, and a catheter was placed to monitor arterial blood pressure (BP). Continuous electrocardiogram (ECG) and heart rate (HR) monitoring were conducted and recorded throughout the procedures.

Subjects were treated with combined intravenous general anesthesia, induced by thiopental (5-10 mg/kg). During tracheostomy, breathing was controlled by a ventilator with a tidal volume of $10-15 \mathrm{ml} / \mathrm{kg}$, respiratory rate of 26-30 breaths/min, and oxygen concentration of 50-60\%. Throughout the procedure, anesthesia was maintained by thiopental (2.5-4.0 mg/kg/h) and vecuronium (0.10-0.15 mg/kg/h).

The heart was exposed by an incision in the center of the chest, and a left ventricular piezometer tube was inserted via the cardiac apex to continuously monitor blood pressure. Standard CPB was established using Fudan-16 uniform membrane oxygenators (Shanghai Fudan Biomaterials Co. Ltd., China) and St. Thomas' cardioplegic solution (19). After aorticocclusion for $60 \mathrm{~min}$, a normal sinus rhythm was restored. The bypass was stopped after 20-30 min of circulatory support, and the vascular catheter was unplugged. All subjects were sacrificed 120 min after surgery by an overdose of $10 \%$ potassium chloride, while remaining in deep anesthesia. Animal hearts were then excised and processed.

Measurement of perioperative hemodynamics. HR, BP, systolic blood pressure (SBP), left ventricular end-systolic pressure (LVESP) and end-diastolic pressure (LVEDP) were measured at 6 time intervals: before $\mathrm{CPB} ; 10 \mathrm{~min}$ after the beginning of the CPB procedure (-10 $\mathrm{min})$, before cardiac arrest; at the time of cardiac arrest ( 0 min); and 10, 30, 60 and $120 \mathrm{~min}$ after aortic opening. Body temperature was measured by anal thermometer and recorded each hour for the first $12 \mathrm{~h}$ following surgery.

Tissue sampling and histological examination. Prior to the establishment of CPB, $0.5 \mathrm{~cm}^{3}$ of right atrial appendage tissue was sampled by thoracotomy. Expression levels of HSP70, Mn-SOD and iNOS were analyzed by immunohistochemical methods. The proportion of apoptotic cells in heart tissues was examined in a $0.5 \mathrm{~cm}^{3}$ sample of right atrial appendage tissue taken 60 min after opening the aorta. All samples were stored in $10 \%$ formaldehyde until analysis. 
Cardiomyocyte apoptosis was examined using a TUNEL In situ Cell Death Detection kit (Roche, USA), according to the instructions provided by the manufacturer. Briefly, heart tissues were paraffin embedded, sliced to $5 \mu \mathrm{m}$ thicknesses, deparaffinized with xylene, and stained with kit reagents for fluorescence microscopy (Olympus, Japan) by a technician in a blinded manner. Positive stained apoptotic cells (PCs) and total cells (TCs) were counted in 3 randomly selected visual fields and the values were used to calculate the apoptosis percentage (AP) for each sample:

$$
\mathrm{AP}=\left(\frac{\mathrm{PC}}{\mathrm{TC}}\right) \times 100
$$

Analysis of HSP70, Mn-SOD and iNOS expression in tissue samples. Sampled tissues were paraffin embedded, sliced to $5 \mu \mathrm{m}$ thicknesses, deparaffinized with xylene, treated with $3 \%$ $\mathrm{H}_{2} \mathrm{O}_{2}$ and goat serum blockers, and subjected to in-sequence heat-induced antigen retrieval. Specimens were incubated with mouse anti-pig HSP70 (1:75), rabbit anti-pig Mn-SOD $(1 \mu \mathrm{g} / \mathrm{ml})$ (both from Stressgen Biotechnologies, Canada), and rabbit anti-human iNOS (1:50; Affinity BioReagents, USA) for $1 \mathrm{~h}$ at $37^{\circ} \mathrm{C}$ or overnight at $4^{\circ} \mathrm{C}$. Specimens were then washed 3 times for 5 min with a sodium perborate (PBS) wash and subsequently incubated with the secondary antibodies FITC-labeled goat anti-mouse IgG (1:100) or TRITC-labeled goat anti-rabbit $\operatorname{IgG}(1: 100)$ for $1 \mathrm{~h}$ at $37^{\circ} \mathrm{C}$. Specimens were again washed 3 times for 5 min with a PBS wash, and resultant slices were mounted with glycerol. These specimens were observed using a fluorescence microscope (Olympus, Japan) by a technician blinded to the experimental grouping. Three visual fields were randomly selected for optical density analysis using a CKS400 imaging system (Zeiss, Germany).

Determination of plasma cTnI and CK-MB. Blood samples were obtained from the right atrium to measure cTnI and CK-MB levels at the same time points: before $\mathrm{CPB} ; 10 \mathrm{~min}$ after the beginning of the CPB procedure $(-10 \mathrm{~min})$, before cardiac arrest; at the time of cardiac arrest ( $0 \mathrm{~min})$; and 10, 30, 60 , and $120 \mathrm{~min}$ after aortic opening. Blood was collected into commercially available EDTA-treated (lavender tops) tubes and plasma was separated by refrigerated centrifugation for $10 \mathrm{~min}$ at $1,000-2,000 \mathrm{x} \mathrm{g}$ followed by $15 \mathrm{~min}$ at $2,000 \mathrm{x} \mathrm{g}$ to deplete platelets.

The liquid component (plasma) was immediately transferred into a clean polypropylene tube using a Pasteur pipette and maintained at $2-8^{\circ} \mathrm{C}$. Alternatively, plasma samples were apportioned into $0.5-\mathrm{ml}$ aliquots and stored at $-20^{\circ} \mathrm{C}$. Blood plasma cTnI was determined by enzyme-linked immunosorbent assay ELISA. Briefly, plasma cTnI concentrations were evaluated by ELISA using a commercially available kit (Biocheck, USA). All plasma samples, negative controls, and standard samples were measured in duplicate, and data were expressed as mean values of the 2 experiments. ELISA was performed according to the manufacturer's instructions, and sample concentrations were calculated from the standard curve. Blood plasma CK-MB levels were determined by $\mathrm{N}$-acetyl-L-cysteine activation.

Correction of postoperative parameters. Due to the dilutional coagulopathy effect of CPB (20), all values of the postop-

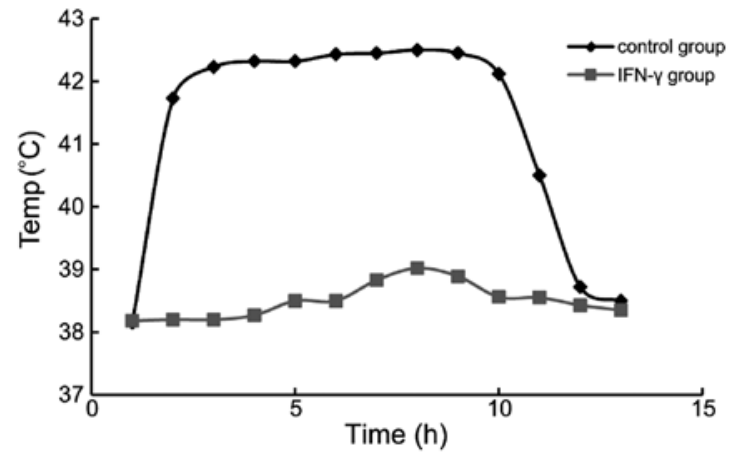

Figure 1. Change in pig body temperature over the $12 \mathrm{~h}$ period following $\mathrm{CPB}$ surgery. CPB, cardiopulmonary bypass.

erative parameters were corrected according to the following formula and subjected to statistical comparison with preoperative values:

$$
\mathrm{Hb}=\left(\frac{\mathrm{Hb}_{\mathrm{i}}}{\mathrm{Hb}_{\mathrm{f}}}\right) \times \mathrm{V}
$$

where $\mathrm{Hb}$ represents the correction value, $\mathrm{Hb}_{\mathrm{i}}$ represents the value prior to $\mathrm{CPB}, \mathrm{Hb}_{\mathrm{f}}$ represents the final value after $\mathrm{CPB}$ and $\mathrm{V}$ represents the measured value.

Statistical analysis. All data are expressed as means \pm standard deviation (SD) and were analyzed using SPSS version 8.0 (SPSS, Inc., Chicago, IL, USA) software. Comparison of the data at each time interval between the 2 groups was performed by t-tests, and at different time intervals between the 2 groups were compared by F-tests followed by Dunnett's tests. P-values $<0.05$ were considered to be statistically different $(\mathrm{P}<0.05)$, and P-values $<0.01$ were considered to be significantly statistically different $(\mathrm{P}<0.01)$.

\section{Results}

Postsurgical body temperature variation. No significant difference in initial body temperatures was observed between the IFN- $\gamma$ group $\left(38.15^{\circ} \mathrm{C}\right)$ and control group $\left(38.18^{\circ} \mathrm{C}\right)$. The IFN- $\gamma$ group evidenced significantly higher body temperature than that observed in the control group by the first hour following surgery $\left(41.70^{\circ} \mathrm{C}\right.$ vs $38.20^{\circ} \mathrm{C}$, respectively). Body temperatures in the IFN- $\gamma$ group remained elevated until a slight decline of $0.15^{\circ} \mathrm{C}$ was observed between postsurgical hours 8 and 9. Between postsurgical hours 9 and 12 , body temperatures in the IFN- $\gamma$ group dropped dramatically from $42.45^{\circ} \mathrm{C}$ to $38.32^{\circ} \mathrm{C}$, values consistent with those observed in the control group $\left(38.35^{\circ} \mathrm{C}\right)$. In the control group, only a slight increase in body temperature of $\sim 0.52^{\circ} \mathrm{C}$ was observed between postsurgical hours $5-7$, declining to $\sim 38.89^{\circ} \mathrm{C}$ by postsurgical hour 9 . The body temperature elevation in the control group was much smaller than that observed in the IFN- $\gamma$ group (Fig. 1).

Changes in perioperative hemodynamics. For all parameters (HR, SBP, LVESP and LVEDP), no significant difference was observed at $-10 \mathrm{~min}$ and at $120 \mathrm{~min}$ following $\mathrm{CPB}$ surgery (Fig. 2). Although no significant differences were observed prior to surgery, significantly lower HR and LVESP were observed in the IFN- $\gamma$ group compared to the 

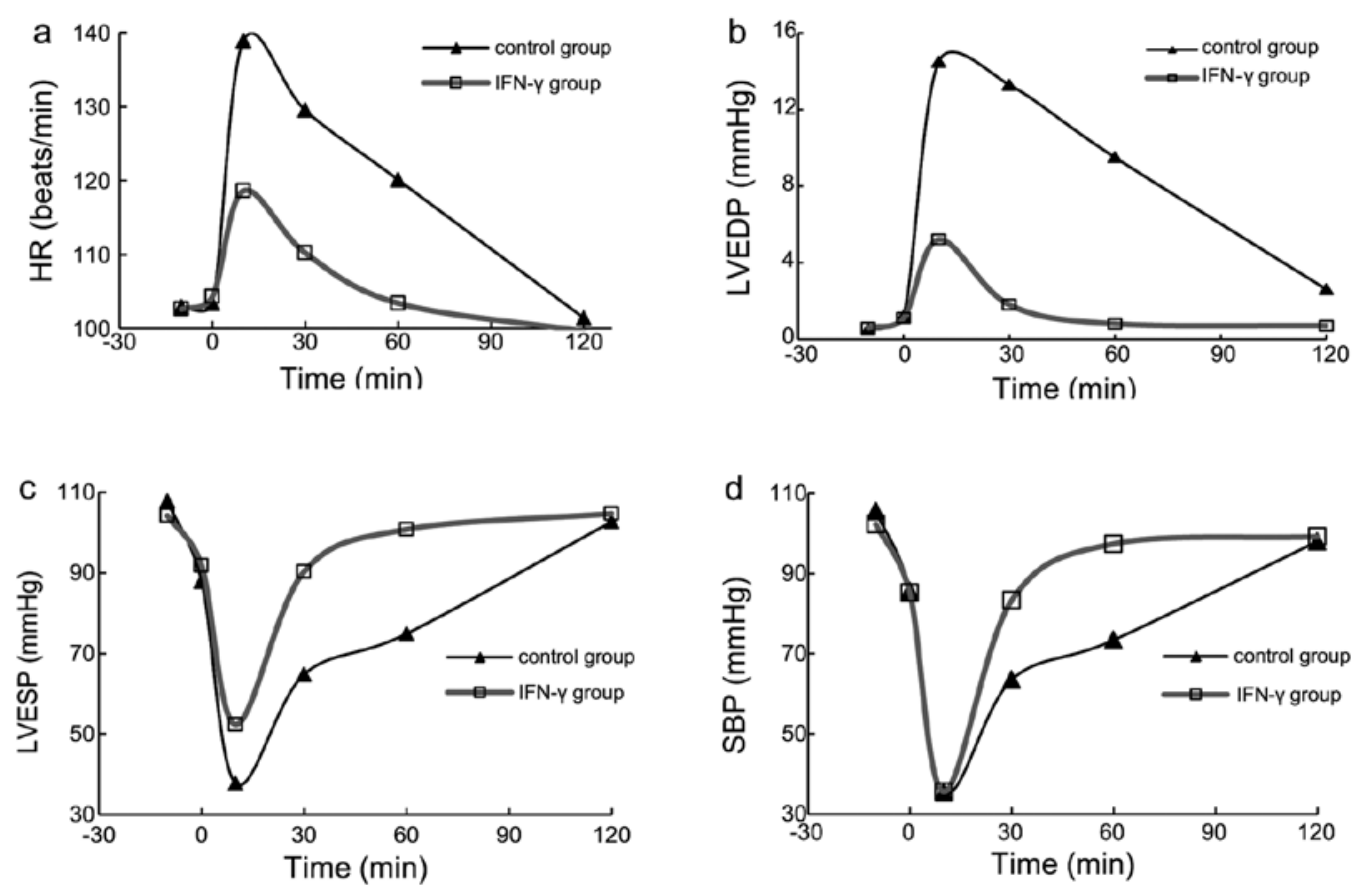

Figure 2. Hemodynamic measurements of porcine subjects from -10 to 120 min after CPB surgery. Shown are values for (a) heart rate (HR), (b) left ventricular end-diastolic pressure (LVEDP), (c) left ventricular end-systolic pressure (LVESP) and (d) systolic blood pressure (SBP). CPB, cardiopulmonary bypass.

control group between 0 and 30 min after CPB surgery. The maximum HR value for the IFN- $\gamma$ group (118.6 beats $/ \mathrm{min})$ was significantly lower than the maximum HR of the control group (138.9 beats/min) observed between 0 and 30 min following surgery. From 30-120 min, HR evidenced steady decreases in both groups, returning to 101.4 beats/min by $120 \mathrm{~min}$ after CPB surgery (Fig. 2a). Similarly, LVEDP peaked between 0 and 30 min after CPB surgery, evidencing a steady decline to normal levels thereafter in both groups. Final LVEDP was slightly higher in the control group $(2.6 \mathrm{mmHg})$ than that in the IFN- $\gamma$ group $(0.7 \mathrm{mmHg}$ ) (Fig. $2 \mathrm{~b})$.

LVESP and SBP were higher in the IFN- $\gamma$ group compared with these values in the control group following CPB surgery. Initial LVESP values were 104.9 and $107.8 \mathrm{mmHg}$ in the IFN $-\gamma$ group and control group, respectively. The minimum LVESP values of $52.4 \mathrm{mmHg}$ in the IFN- $\gamma$ group and $37.7 \mathrm{mmHg}$ were achieved between 0 and $30 \mathrm{~min}$ after CPB surgery. Initial SBP values were 102.3 and $105.5 \mathrm{mmHg}$ in the IFN- $\gamma$ group and control group, respectively. Minimum SBP of $35.6 \mathrm{mmHg}$ in the IFN- $\gamma$ group and $35.6 \mathrm{mmHg}$ in the control group were achieved between 0 and $30 \mathrm{~min}$ after CPB surgery (Fig. 2d). Although both groups showed a steady increase in LVESP and SBP values between 30 and $120 \mathrm{~min}$ after surgery, the IFN- $\gamma$ group more quickly recovered normal LVESP $(104.7-102.7 \mathrm{mmHg})$ and SBP $(98-99.2 \mathrm{mmHg})$ levels (Fig. 2c).

Changes in perioperative enzyme expression in myocardial tissues. Although initial values for $\mathrm{cTnI}$ were not significantly different between the IFN- $\gamma$ group $(3.70 \mathrm{ng} / \mathrm{ml})$ and the control group $(4.20 \mathrm{ng} / \mathrm{ml})(\mathrm{P}>0.05), \mathrm{cTnI}$ in the control group was much lower following CPB surgery $(\mathrm{P}<0.01)$. In both groups, the rate of increase was largest between 0 and $60 \mathrm{~min}$ after CPB surgery, evidencing a slower rate of increase from 60 and

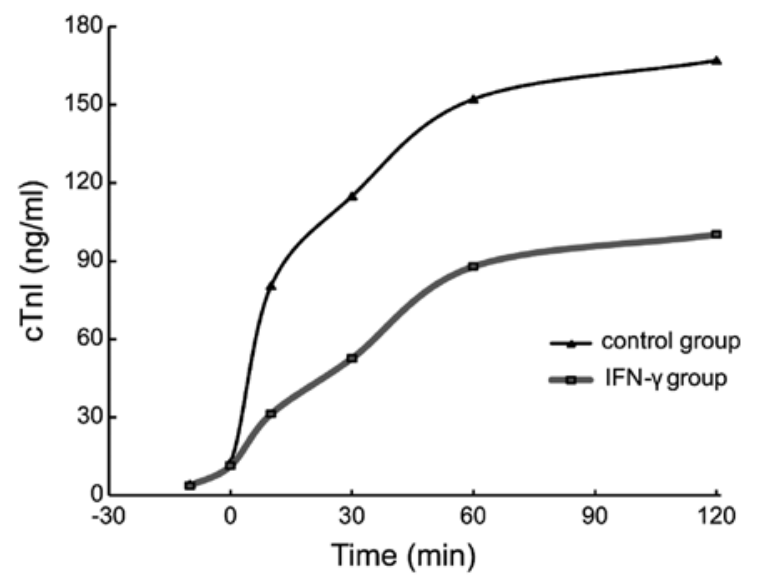

Figure 3. Measurement of cTnI of porcine subjects from -10 to $120 \mathrm{~min}$ after CPB surgery. cTnI, cardiac troponin I; CPB, cardiopulmonary bypass.

120 min after surgery. The maximum cTnI level achieved by the IFN- $\gamma$ group $(100.12 \mathrm{ng} / \mathrm{ml})$ was significantly lower than that achieved by the control group (166.98 ng/ml) (Fig. 3). Notably, plasma cTnI concentrations were significantly lower in the IFN- $\gamma$ group at each time point after opening of the aorta than those of the control group $(\mathrm{P}<0.01)$.

Similarly, no significant difference in CK-MB activity was observed before CPB surgery in the IFN- $\gamma$ group (2074.0 U/l) and the control group (1987.6 U/l) $(\mathrm{P}>0.05)$; however, overall increases in CK-MB activity were significantly lower in the IFN- $\gamma$ group compared with the control group by $120 \mathrm{~min}$ $(\mathrm{P}<0.01)$. Both groups showed a dramatic increase between -10 and $30 \mathrm{~min}$, followed by a gradual decrease from 30 and $120 \mathrm{~min}$. The final CK-MB activity value was significantly lower in the IFN- $\gamma$ group (3015.9 U/l) compared to 


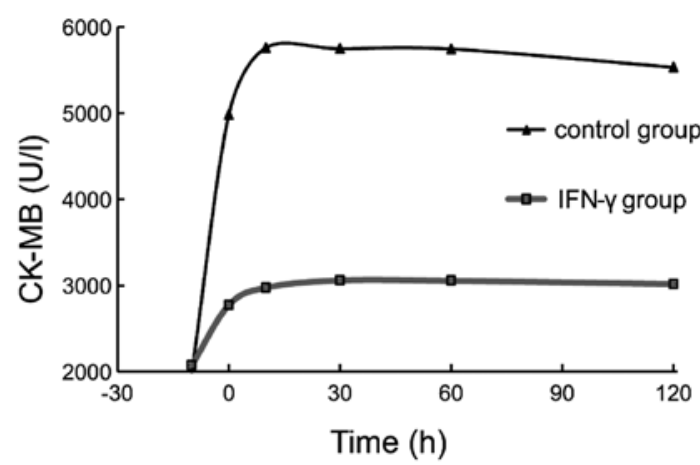

Figure 4. Measurement of CK-MB activity of porcine subjects from -10 to 120 min after CPB surgery. CK-MB, creatine kinase isoenzyme-MB; CPB, cardiopulmonary bypass.

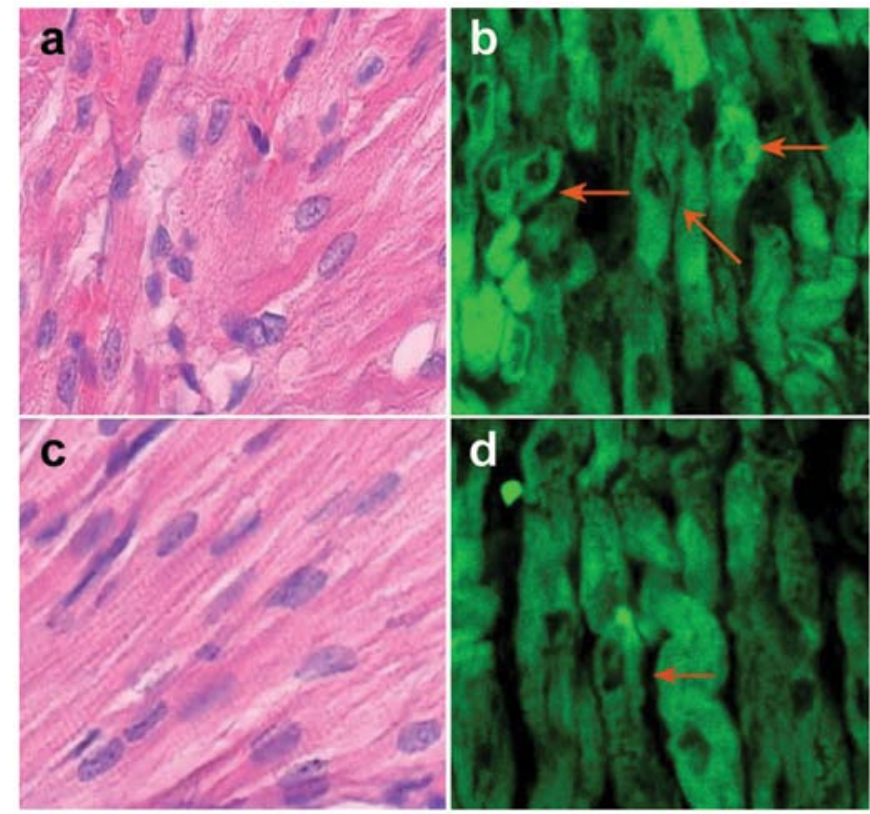

Figure 5. Postoperative myocardial tissue staining results (magnification, x400). (a) Postoperative myocardial H\&E staining of the control group, demonstrating obvious morphological disorders of cardiomyocytes and interstitial congestion; (b) TUNEL staining of myocardial sections of the control group after surgery, showing apoptotic myocardial cells $(\leftarrow)$. (c) Postoperative H\&E staining of the IFN- $\gamma$ group, demonstrating no obvious myocardial cell disorders; however, mild interstitial congestion was present. (d) Postoperative TUNEL staining of myocardial sections of the IFN $-\gamma$ group, showing apoptosis in cardiomyocytes $(\leftarrow)$. IFN $-\gamma$, interferon- $\gamma$; TUNEL, terminal deoxynucleotidyl-transferase-mediated dUTP nick end labeling. $\mathrm{H} \& \mathrm{E}$, hematoxylin and eosin.

$5531.8 \mathrm{U} / 1$ in the control group (Fig. 4). Notably, changes in CK-MB paralleled changes in cTnI throughout the observation period.

Cardiomyocyte apoptosis. In the control group, hematoxylin and eosin (H\&E) staining of postoperative myocardial tissue revealed cloudy, swollen cardiomyocytes with notable morphological disorders and significant myocardial interstitial congestion (Fig. 5a). TUNEL results showed significant apoptosis of cardiomyocytes (Fig. 5b) with an apoptotic ratio of $18.30 \pm 2.69 \%$. In the IFN $-\gamma$ group, pretreatment with INF- $\gamma 24 \mathrm{~h}$ before surgery led to mild, cloudy swelling and
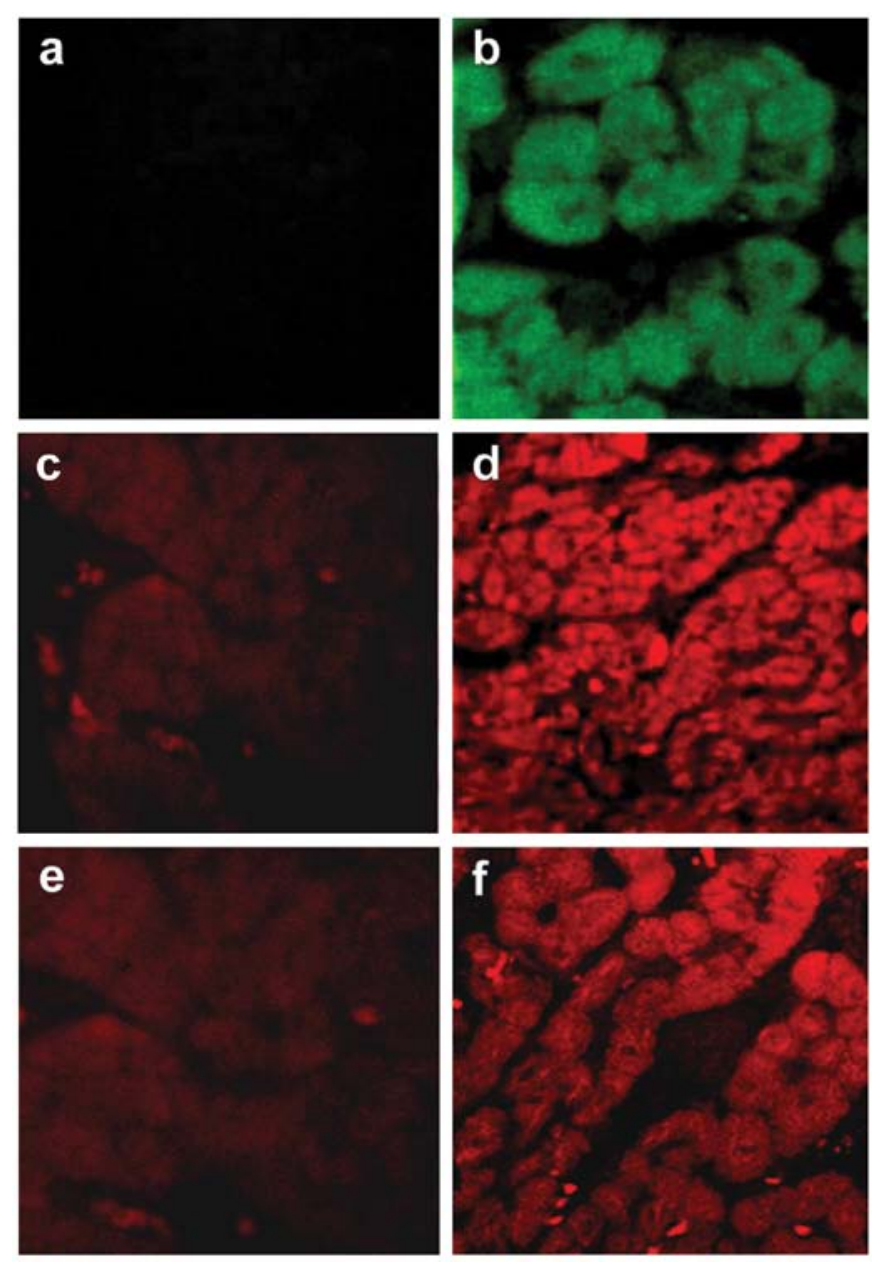

Figure 6. Immunofluorescence staining of HSP70, Mn-SOD and iNOS (magnification, $x 400$ ). (a) Immunofluorescence staining of HSP70 in preoperative myocardial tissues of the control group, demonstrating no HSP70 expression. (b) HSP70 staining in preoperative myocardial tissues of the IFN- $\gamma$ group, demonstrating high levels of HSP70 expression. (c) Preoperative expression of myocardial Mn-SOD in the control group, demonstrating very low levels of Mn-SOD expression. (d) Preoperative expression of myocardial Mn-SOD in the IFN- $\gamma$ group, demonstrating significantly elevated Mn-SOD expression. (e) Scarce iNOS expression was detected in the preoperative myocardium of the control group. (f) Elevated levels of iNOS expression were detected in the preoperative myocardium of the IFN- $\gamma$ group. HSP70, heat shock protein 70 ; Mn-SOD, Mn-superoxide dismutase; iNOS, inducible nitric oxide synthase; IFN- $\gamma$, interferon- $\gamma$.

no obvious morphological disorders in cells or myocardial interstitial congestion (Fig. 5c). Cardiomyocyte apoptosis was not apparent in the TUNEL assay (Fig. 5d), and a significantly lower apoptotic ratio of $5.16 \pm 1.22 \%$ was observed in the IFN- $\gamma$ group $(\mathrm{P}<0.01)$.

Myocardial protein expression. No HSP70 expression was detected in myocardial cells in the control group using immunofluorescence staining (Fig. 6a). The same analytical technique, however, produced positive results for HSP70 expression in myocardial cells of the IFN- $\gamma$ group, characterized by uniform distribution of green fluorescence throughout the cytoplasm (Fig. 6b). The expression level was significantly higher than that of the control group $(\mathrm{P}<0.01)$. Overall, the expression level of HSP70 in the myocardial tissues of the IFN- $\gamma$ group was significantly higher than that of the control 
Table I. Myocardial protein HSP70, Mn-SOD and iNOS expression in the IFN- $\gamma$ and control groups.

\begin{tabular}{lcccc}
\hline Proteins & $\begin{array}{c}\text { Control group } \\
(\mathrm{n}=10)\end{array}$ & $\begin{array}{c}\text { IFN- } \gamma \text { group } \\
(\mathrm{n}=10)\end{array}$ & T-value & P-value \\
\hline HSP70 & $0.00 \pm 0.00$ & $0.67 \pm 0.03$ & -39.223 & $<0.001$ \\
Mn-SOD & $0.12 \pm 0.03$ & $0.77 \pm 0.03$ & -42.909 & $<0.001$ \\
iNOS & $0.08 \pm 0.02$ & $0.56 \pm 0.05$ & -30.326 & $<0.001$ \\
\hline
\end{tabular}

HSP70, heat shock protein 70; Mn-SOD, Mn-superoxide dismutase; iNOS, inducible nitric oxide synthase; IFN- $\gamma$, interferon- $\gamma$.

group $(\mathrm{P}<0.01)$, indicating less myocardial injury and improved myocardial protection.

Immunofluorescence staining revealed very limited expression of Mn-SOD in the myocardial cells of the control group (Fig. 6c). Conversely, expression levels of Mn-SOD in myocardial cells of the IFN- $\gamma$ group were significantly higher $(\mathrm{P}<0.01)$, as indicated by red fluorescence distributed throughout the cytoplasm (Fig. 6d).

Only very low levels of iNOS expression were detected in myocardial cells of the control group (Fig. 6e). Conversely, iNOS expression in the IFN- $\gamma$ group was high, as indicated by red fluorescence distributed in the entirety of the cytoplasm (Fig. 6f). The difference in iNOS expression between the 2 groups was significant $(\mathrm{P}<0.01)$.

The optical densities were calculated based on immunofluorescence images of HSP70, Mn-SOD and iNOS. As shown in Table I, expression levels for all 3 of these myocardial proteins were significantly higher in the IFN- $\gamma$ group than values in the control group $(\mathrm{P}<0.01)$.

\section{Discussion}

Cardiac preconditioning aims to maintain normal enzyme levels and prevent apoptosis in cardiac cells during ischemia. Following treatment with IFN- $\gamma 24 \mathrm{~h}$ prior to CPB surgery, expression of cardiac proteins HSP70, Mn-SOD and iNOS increased while cTnI and CK-MB activation decreased in the porcine CPB models. Although no significant differences in initial measurements existed between the IFN- $\gamma$ and control group subjects, pigs treated with IFN- $\gamma$ evidenced smaller peak abnormalities in HR, LVESP, LVEDP and SBP at 120 min and higher body temperatures in the first $12 \mathrm{~h}$ following surgery. Thus, preoperative IFN- $\gamma$ treatment may provide clinically useful preconditioning by reducing detrimental enzyme levels following reperfusion and by upregulating beneficial HSPs.

Modern technology has reduced the invasiveness and blood loss in CPB. CPB surgeries, however, still generally require occlusion of the superior and inferior venae cavae to ensure a clear operative field (21), often resulting in damage and high mortality during reperfusion (22). Cardiac reperfusion injury primarily manifests as myocardial contractile dysfunction (myocardial stunning) (23), cardiac enzyme leakage (24), and apoptotic myocardial cells (6). Most notably, damage to myocardial cells during reperfusion results in enzyme release into the systemic blood supply, measurable in the plasma.
Measurement of plasma cTnI is considered the most reliable detector of myocardial damage, and moderating cTnI and related myocardial CK-MB levels has been suggested for myocardial protection (24). Onorati et al (24) reported that perioperative enoximone infusion improved cardiac enzyme release after $\mathrm{CPB}$, demonstrating significant reductions in cTnI and moderate reductions in CK-MB. A similar study by Boldt et al (25) showed that pharmacologic interventions applied before the start of CPB most effectively protected the heart from ischemia-reperfusion injury by reducing postsurgical cTnI levels. The present study reported that the rapid increase in cTnI following reperfusion was reduced after surgery, consistent with previous reports. CK-MB levels paralleled $\mathrm{cTnI}$ levels throughout the observation period, suggesting IFN- $\gamma$ reduces overall myocardial injury.

Apoptosis of cardiomyocytes is associated with heart failure and ischemic injury following reperfusion (26). Reperfusion has been linked to accelerated apoptotic cell death in cardiomyocytes, impairing heart tissues (12). Brief ischemic periods can stimulate apoptosis, resulting in protective apoptotic inhibitor Bcl-2 and Bax production, potentially involved in apoptosis prevention (27). Additionally, upregulation of FAS receptors occurs in failing cardiomyocytes, leading to cell apoptosis (28). Thus, preconditioning treatment with IFN- $\gamma$ may enhance the production of anti-apoptotic compounds and potentially prevent FAS activation, thus significantly alleviating myocardial tissue injury by reducing cell apoptosis.

Numerous reports have debated the mechanism of cardiacischemic reperfusion injury, although the involvement of HSPs, Mn-SOD, and iNOS is well established. HSPs, particularly HSP70, protect cells from damage by extreme conditions (29). HSP70 upregulation facilitates normal cell growth, protects vessel endothelial cells and repairs protein damage (30). Notably, elevated levels of HSP70 can reduce necrosis in heart and liver tissues subjected to ischemic conditions, although apoptotic effects were not reported (29). The abundant expression of HSP70 in current IFN- $\gamma$-treated subjects demonstrates the potential protective effect of HSP70 during ischemia in CPB.

Similarly, Mn-SOD, catalase, and Bcl-2 have been shown to play roles in cleaning cellular reactive oxygen species (ROS), preventing apoptosis (31). In the present study, elevated Mn-SOD levels in IFN- $\gamma$-treated subjects suggest that reduced ROS damage to myocardial cells during cardiac ischemia-reperfusion injury may contribute to reduced tissue damage. Since HSP70 can induce endogenous antioxidant enzymes and increase their activity, IFN- $\gamma$ may act through HSP70 to indirectly induce increased Mn-SOD expression, meriting further study.

The impact of the important signaling molecule nitric oxide (NO) in cardiomyocytes during myocardial ischemia and reperfusion has resulted in conflicting reports of protective, deleterious, or null effects (32). Since NO is generated from L-arginine by nitric oxide synthase (NOS), levels of endothelial NOS (eNOS), neuronal NOS (nNOS), and inducible NOS (iNOS) can be examined to draw conclusions about cellular NO levels. While the constructive NOSs (cNOS) eNOS and nNOS occur in normal myocardium tissues, iNOS is only expressed when tissues are subjected to stimuli (33). When activated, iNOS produces high levels of NO to exert 
its biological effects. Compared with cNOSs, iNOS releases NO slowly after stimulation but sustains this release for longer periods (34). Consistent with the characteristics of iNOS as previously described, IFN- $\gamma$ pretreatment appeared late but maintained its protective effect for a relatively long period.

NO may be more important to the cardioprotective effect provided by preconditioning as previously thought, as suggested by applications of NO-donor drugs (35). Possible mechanisms of NO action include: i) activation of guanylate cyclase to produce cGMP, activating protein kinase $\mathrm{G}$ and opening mitochondrial potassium channels (36); ii) inhibition of platelet aggregation and thrombosis, reducing neutrophil infiltration and elevating inflammatory mediator release (37); iii) increased antioxidant enzymes and antioxidant response activity (38); iv) activation of COX-2 through PGE2 and PGI2 and enhanced coronary vasodilation (39), and v) prevention of intracellular calcium overload (40). Sareila et al (41) reported that IFN- $\gamma$ induced expression of iNOS. Similarly, in the present study, IFN- $\gamma$-treated subjects exhibited elevated iNOS levels, suggesting protective upregulation of iNOS expression and increases in endogenous NO.

The recognized protective effect of NO provides a theoretical basis for IFN- $\gamma$ pretreatment for cardiac ischemiareperfusion injury preconditioning involving release of endogenous NO over exogenous NO release. Benefits include i) site-specific release at the interface of endothelium and plasma with phase-specific reperfusion; ii) distribution independent of coronary blood flow; and iii) effective regulation of overproduction (35). The full mechanisms involved in these interactions, however, require further research prior to clinical recommendations.

In conclusion, IFN- $\gamma$ preconditioning administered $24 \mathrm{~h}$ prior to CPB surgery alleviated symptoms of ischemic-reperfusion injury following $\mathrm{CPB}$ in in vivo porcine models, likely due to increased expression of HSP70, Mn-SOD and iNOS. Impaired cardiac function recovery, cardiac enzyme leakage, and apoptosis were reduced with IFN $-\gamma$ preconditioning, suggesting a protective effect on myocardium tissues during the late phase of CPB. Expression levels of HSP70, Mn-SOD and iNOS were slightly elevated in myocardial cells treated with IFN- $\gamma$ and apoptosis was reduced. IFN- $\gamma$ preconditioning is a viable alternative to drug-induced late preconditioning for endogenous myocardial protection during open heart surgery.

\section{References}

1. Pinto DS, Gibson CM and Wykrzykowska JJ: Ischemic reperfusion injury of the heart. (Literature Review). Wolters-Kluwer Health, 2012

2. Nolan SP, Zacour R and Dammann JF: Reflections on the evolution of cardiopulmonary bypass. Ann Thorac Surg 64: 1540-1543, 1997.

3. Murphy GJ and Angelini GD: Side effects of cardiopulmonary bypass: what is the reality? J Card Surg 19: 481-488, 2004.

4. Sheehan FH, Doerr R, Schmidt WG, et al: Early recovery of left ventricular function after thrombolytic therapy for acute myocardial infarction: an important determinant of survival. J Am Coll Cardiol 12: 289-300, 1988.

5. Egan JR, Butler TL, Cole AD, et al: Myocardial ischemia is more important than the effects of cardiopulmonary bypass on myocardial water handling and postoperative dysfunction: a pediatric animal model. J Thorac Cardiovasc Surg 136: 1265-1273, 2008.

6. Kovacević M, Simić O, Jonjić N and Stifter S: Apoptosis and cardiopulmonary bypass. J Card Surg 22: 129-134, 2007.
7. Perrault LP and Menasché P: Preconditioning: can nature's shield be raised against surgical ischemic-reperfusion injury? Ann Thorac Surg 68: 1988-1994, 1999.

8. Murry CE, Jennings RB and Reimer KA: Preconditioning with ischemia: a delay of lethal cell injury in ischemic myocardium. Circulation 74: 1124-1136, 1986.

9. Goto M, Liu Y, Yang XM, Ardell JL, Cohen MV and Downey JM: Role of bradykinin in protection of ischemic preconditioning in rabbit hearts. Circ Res 77: 611-621, 1995.

10. Przyklenk K, Kloner RA and Yellon DM (eds): Ischemic Preconditioning: The Concept of Endogenous Cardioprotection. Kluwer Academic Publishers, Boston, 1994.

11. Lee HT: Mechanisms of ischemic preconditioning and clinical implications for multiorgan ischemic-reperfusion injury. J Cardiothorac Vasc Anesth 13: 78-91, 1999.

12. Valen G: The basic biology of apoptosis and its implications for cardiac function and viability. Ann Thorac Surg 75: S656-S660, 2003.

13. Kajstura J, Cigola E, Malhotra A, et al: Angiotensin II induces apoptosis of adult ventricular myocytes in vitro. J Mol Cell Cardiol 29: 859-870, 1997.

14. Geng YJ, Wu Q, Muszynski M, Hansson GK and Libby P: Apoptosis of vascular smooth muscle cells induced by in vitro stimulation with interferon- $\gamma$, tumor necrosis factor- $\alpha$, and interleukin-1ß. Arterioscler Thromb Vasc Biol 16: 19-27, 1996.

15. Joyeux M, Godin-Ribuot D, Yellon DM, Demenge P and Ribuot C: Heat stress response and myocardial protection. Fundam Clin Pharmacol 13: 1-10, 1999.

16. Das DK, Maulik N and Moraru II: Gene expression in acute myocardial stress. Induction by hypoxia, ischemia, reperfusion, hyperthermia and oxidative stress. J Mol Cell Cardiol 27: 181-193, 1995.

17. Csont T, Viappiani S, Sawicka J, et al: The involvement of superoxide and iNOS-derived NO in cardiac dysfunction induced by pro-inflammatory cytokines. J Mol Cell Cardiol 39: 833-840, 2005.

18. Knaapen MW, Davies MJ, De Bie M, Haven AJ, Martinet W and Kockx MM: Apoptotic versus autophagic cell death in heart failure. Cardiovasc Res 51: 304-312, 2001.

19. Jynge P, Hearse DJ, Feuvray D, et al: The St. Thomas' hospital cardioplegic solution: a characterization in two species. Scand J Thorac Cardiovasc Surg (Suppl 30): 1-28, 1981.

20. Brinkman AC, Romijn JW, van Barneveld LJ, et al: Profound effects of cardiopulmonary bypass priming solutions on the fibrin part of clot formation: an ex vivo evaluation using rotation thromboelastometry. J Cardiothorac Vasc Anesth 24: 422-426, 2010.

21. Gullu AU, Senay S, Kocyigit M and Alhan C: A simple method for occlusion of both venae cavae in total cardiopulmonary bypass for robotic surgery. Interact Cardiovasc Thorac Surg 14: 138-139, 2012.

22. Weisel RD, Mickle DA, Finkle CD, Tumiati LC, Madonik MM and Ivanov J: Delayed myocardial metabolic recovery after blood cardioplegia. Ann Thorac Surg 48: 503-507, 1989.

23. Takahashi T: Toll-like receptors and myocardial contractile dysfunction. Cardiovasc Res 78: 3-4, 2008.

24. Onorati F, Renzulli A, De Feo M, et al: Perioperative enoximone infusion improves cardiac enzyme release after CABG. J Cardiothorac Vasc Anesth 18: 409-414, 2004.

25. Boldt J, Rothe G, Schindler E, Doll C, Görlach G and Hempelmann G: Can clonidine, enoximone, and enalaprilat help to protect the myocardium against ischaemia in cardiac surgery? Heart 76: 207-213, 1996.

26. Pexieder T: Cell death in the morphogenesis and teratogenesis of the heart. Adv Anat Embryol Cell Biol 51: 3-99, 1975.

27. James TN: Normal and abnormal consequences of apoptosis in the human heart. From postnatal morphogenesis to paroxysmal arrhythmias. Circulation 90: 556-573, 1994.

28. Dominov JA, Houlihan-Kawamoto CA, Swap CJ and Miller JB: Pro- and anti-apoptotic members of the Bcl-2 family in skeletal muscle: a distinct role for Bcl-2 in later stages of myogenesis. Dev Dyn 220: 18-26, 2001.

29. Yavuz S, Kasap M, Parlar H, et al: Heat shock proteins and myocardial protection during cardiopulmonary bypass. J Int Med Res 39: 499-507, 2011

30. Anselmi A, Abbate A, Girola F, et al: Myocardial ischemia, stunning, inflammation, and apoptosis during cardiac surgery: a review of evidence. Eur J Cardiothorac Surg 25: 304-311, 2004. 
31. Wang L, Li W, Kang Z, et al: Hyperbaric oxygen preconditioning attenuates early apoptosis after spinal cord ischemia in rats. J Neurotrauma 26: 55-66, 2009.

32. Sellke FW: Vascular changes after cardiopulmonary bypass and ischemic cardiac arrest: roles of nitric oxide synthase and cyclooxygenase. Braz J Med Biol Res 32: 1345-1352, 1999.

33. Toprak V, Sirin BH, Tok D, Ozbilgin K and Saribülbül O: The effect of cardiopulmonary bypass on the expression of inducible nitric oxide synthase, endothelial nitric oxide synthase, and vascular endothelial growth factor in the internal mammary artery. J Cardiothorac Vasc Anesth 20: 63-67, 2006.

34. Papapetropoulos A, Andreopoulos S, Go CY, Hoque A, Fuchs LC and Catravas JD: Regulation of the nitric oxide synthase-nitric oxide-cGMP pathway in rat mesenteric endothelial cells. J Appl Physiol 91: 2553-2560, 2001.

35. Bolli R: Cardioprotective function of inducible nitric oxide synthase and role of nitric oxide in myocardial ischemia and preconditioning: an overview of a decade of research. J Mol Cell Cardiol 33: 1897-1918, 2001.

36. Stone JR and Marletta MA: Spectral and kinetic studies on the activation of soluble guanylate cyclase by nitric oxide. Biochemistry 35: 1093-1099, 1996.
37. Nong Z, Hoylaerts M, Van Pelt N, Collen D and Janssens S: Nitric oxide inhalation inhibits platelet aggregation and plateletmediated pulmonary thrombosis in rats. Circ Res 81: 865-869, 1997.

38. del Río LA, Corpas FJ, Sandalio LM, Palma JM, Gómez M and Barroso JB: Reactive oxygen species, antioxidant systems and nitric oxide in peroxisomes. J Exp Bot 53: 1255-1272, 2002.

39. Yoon T, Cheon MS, Lee AY, et al: Anti-inflammatory activity of methylene chloride fraction from Glehnia littoralis extract via suppression of $\mathrm{NF}-\kappa \mathrm{B}$ and mitogen-activated protein kinase activity. J Pharmacol Sci 112: 46-55, 2010.

40. Rickover O, Zinman T, Kaplan D and Shainberg A: Exogenous nitric oxide triggers classic ischemic preconditioning by preventing intracellular $\mathrm{Ca}^{2+}$ overload in cardiomyocytes. Cell Calcium 43: 324-333, 2008.

41. Sareila O, Korhonen R, Kärpänniemi O, Nieminen R, Kankaanranta $\mathrm{H}$ and Moilanen E: JAK inhibitors AG-490 and WHI-P154 decrease IFN- $\gamma$-induced iNOS expression and NO production in macrophages. Mediators Inflamm 2006: 16161, 2006. 